\title{
GÊNERO E SEXUALIDADE NA UNIVERSIDADE - UMA DISCUSSÃO POSSÍVEL? ${ }^{1}$
}

\author{
GENDER AND SEXUALITY IN THE UNIVERSITY - A POSSIBLE \\ DISCUSSION?
}

\author{
Agda Cristhina de Medeiros Batista² \\ Maria Gabriella Conceição Gabriel ${ }^{3}$ \\ Sabrina Xavier de Oliveira ${ }^{4}$ \\ Angelita Lúcia de Albuquerque Sousa ${ }^{5}$ \\ Lúcia Maria Temóteo 6
}

\begin{abstract}
RESUMO: Objetivo: Discutir a temática de gênero e sexualidade na universidade. Método: Trata-se de uma pesquisa de intervenção de abordagem qualitativa, realizada em uma Instituição de Ensino Superior localizada no interior da Paraíba. A amostra foi composta por vinte e dois discentes concluintes de um curso da área da saúde. Para realização da intervenção foram planejados três encontros, nos quais aplicaram-se questionários, rodas de conversa e apresentação de vídeos sobre a temática. Resultados: Como resultado, viu-se como o machismo ainda se faz presente no nosso contexto social, sendo perpetuado em discursos como "na questão de roupa curta, eu deixaria de usar em respeito ao meu namorado". A partir de tais concepções, nota-se a necessidade de discussões e reflexões que envolvam a temática. Outro aspecto constatado com base nessa pesquisa refere-se às brincadeiras infantis, as quais alguns discentes achavam errada a ideia de meninos brincarem com objetos culturalmente direcionados a meninas, já que supostamente estes brinquedos os "tornariam" homossexuais. Verificou-se também o modo como as concepções patriarcais estão enraizadas no ambiente acadêmico, assim como no cotidiano em geral. Considerações finais: As falas dos participantes evidenciam a necessidade de discutir a temática do gênero e da sexualidade na universidade, visto que, apesar desse assunto ter certa visibilidade atualmente, os indivíduos ainda confundem muito as novas denominações de gênero, bem como a temática no
\end{abstract}

\footnotetext{
$1 \mathrm{O}$ artigo é parte do resultado de uma pesquisa realizada em 2018, intitulada Gênero e Sexualidade na Academia, cujo parecer aprovado pelo CEP é: CAAE: 13328119.8.0000.5180.

2 Estudante do $8^{\circ}$ período do curso de Psicologia da Faculdade Santa Maria - FSM.

3 Estudante do $8^{\circ}$ período do curso de Psicologia da Faculdade Santa Maria - FSM.

${ }^{4}$ Estudante do $10^{\circ}$ período do curso de Psicologia da Faculdade Santa Maria - FSM.

${ }^{5}$ Graduada em Psicologia pela Faculdade Santa Maria - FSM.

6 Licenciada em Psicologia, Mestra em Educação, Professora de Psicologia da Faculdade Santa Maria, Membro da Sociedade Psicanalítica da Paraíba.
} 
geral. Desse modo, é necessário que essas discussões façam parte do meio acadêmico como forma de desconstruir o pensamento que, na maioria das vezes, é repassado de maneira distorcida.

Palavras chave: Gênero; Sexualidade; Ensino Superior; Machismo.

ABSTRACT: Objective: To discuss gender and sexuality at university. Method: This is an intervention research with a qualitative approach, carried out in a Higher Education Institution located in the interior of Paraiba. The sample consisted of twenty-two graduates of a Health course. To carry out the intervention, three meetings were planned, in which questionnaires, talks and video presentations on the subject were applied. Results: As a result, it was seen how machismo is still present in our social context, being perpetuated in speeches like "I would stop wearing short clothes in respect to my boyfriend". Based on such conceptions, we note the need for discussions and reflections that involve the theme. Another aspect of this research is related to children's games, which some students found wrong with the idea of boys playing with objects culturally directed at girls, since supposedly these toys would "make them" homosexuals. It was also verified how patriarchal conceptions are rooted in the academic environment, as well as in daily life in general. Final remarks: The participants' statements highlight the need to discuss gender and sexuality at the university, since although this subject has a certain visibility today, the individuals still confuse the new gender denominations, as well as the theme in general. Thus, it is necessary that these discussions are part of the academic environment as a way of deconstructing the thinking that, in most cases, is passed on in a distorted way.

Keywords: Gender; Sexuality; Higher Education; Machismo. 


\section{INTRODUÇÃO}

Conforme aponta Beauvoir (1967), "Ninguém nasce mulher: torna-se", podese compreender que ser mulher ou homem é uma construção social e que vai além do caráter biológico ou genético. Esse pensamento vem influenciando as discussões acerca da identidade de gênero, tanto no interior dos movimentos de mulheres quanto na Academia. Louro (2008) ressalta essa concepção ao discutir os vários espaços sociais vivenciados pelos sujeitos e a sua influência na construção de gênero. A autora faz questão de reafirmar que a condição biológica não é suficiente para dizer-se feminino ou masculino.

Este artigo é fruto de uma experiência vivenciada pelas autoras enquanto participantes de um projeto de pesquisa intitulado "Gênero e Sexualidade na Academia". Este foi realizado em espaços de sala de aula com estudantes de um curso da área da saúde de uma Instituição de Ensino Superior (IES) do sertão paraibano, no período de março a maio de 2018.

Foram realizados três encontros com a finalidade de discutir a temática proposta pelo projeto. O material colhido do primeiro encontro é a fonte de inspiração para o desenvolvimento do presente artigo. Desse modo, foi solicitado aos participantes que respondessem a um questionário envolvendo questões relacionadas à temática, com a intenção de traçar o perfil do grupo. Em seguida, foi exibido um vídeo que teve como propósito exemplificar, de maneira irônica, os comportamentos machistas da sociedade e as relações de gênero, buscando provocar uma discussão com os alunos sobre o que foi exposto, e a partir disso permitir compreender as opiniões da turma acerca do tópico e posteriormente analisá-las. 


\section{SEXO, GÊNERO E FEMINISMO - ALGUMAS CONSIDERAÇÕES}

Gurgel (2010) diz que o movimento feminista teve a sua primeira expressão na França em 1789, e desde então busca desenvolver ações que fortaleçam a igualdade e a liberdade da mulher perante a sociedade, quebrando os mecanismos e elementos que promovam a desigualdade entre as mulheres e homens no meio onde estão inseridos. Em 1868 foi fundada nos Estados Unidos a primeira associação feminista, denominada "Liga das Mulheres", que se desenvolveu durante a luta em relação ao direito do trabalho. Houve grande resistência dos demais trabalhadores à luta empreendida pela Liga, pois acreditavam que a presença das mulheres ameaçava seus empregos e falsificava seu papel social. Tal reação provocou inquietação nas mulheres socialistas, que fizeram manifestações e reivindicações em busca de efetivar seus direitos. (GURGEL, 2010).

Setores da literatura feminista costumam descrever a evolução do movimento feminista a partir das chamadas "ondas". Assim, a discussão sobre gênero começa no período do Sufragismo, datado do fim do século XIX até meados do século XX, considerado a primeira onda do feminismo. O movimento sufragista se caracterizava pela luta das mulheres ao direito ao voto, ao trabalho e ao estudo, e não se deter apenas ao âmbito familiar.

Ainda dentro da ação desenvolvida pelas mulheres, ocorre nos anos 60 a segunda onda do movimento feminista, período cujo feminismo tomou força e partiu para além das questões sociopolíticas, levando em consideração não somente as críticas e pensamentos levantados sobre o movimento, mas também começou a viabilizar questões teóricas, o que contribuiu para o surgimento de novos conceitos atribuídos ao gênero. (LOURO, 2003).

Além destas, por volta da década de 90 acontece a terceira onda do feminismo, como resposta aos questionamentos e propostas anteriores. Nesta época, havia muitas críticas relacionadas às questões dos direitos humanos e do respeito a todos, levando em consideração a sua diversidade. Essa fase do movimento buscou viabilizar e valorizar demandas relacionadas aos grupos de 
pessoas consideradas minorias na sociedade, como por exemplo os homossexuais e os negros, não somente as mulheres. Ademais, não levava em considerações questões que generalizavam as realidades das mulheres (ZARANKIN, SARLENO, 2008/2009).

Além das áreas de conhecimento baseadas em Sociologia e Política, outros setores da ciência também passaram a estudar a problemática de gênero, como no caso da Arqueologia e da Antropologia (LOURO, 2003). A partir de então, conceitos como sexo e gênero passam a ser elaborados de uma melhor forma, como aponta Zarankin e Sarlerno (2008/2009):

Durante a década de 1970, a antropologia começou a diferenciar os conceitos de sexo e gênero. Desta forma, estabeleceu que o sexo compreendia as diferenças biológicas entre os corpos de mulheres e homens, enquanto o gênero correspondia a uma redefinição cultural dessas diferenças (ZARANKIN, SARLERNO, 2008/2009, p. 222-223).

Embora sejam constantemente usados como sinônimos, há diferenças entre os termos sexo e gênero. De acordo com Zarankin e Salerno (2008/2009, p.221), "O gênero constitui uma categoria de análise própria das ciências sociais que se refere à construção cultural dos papéis e das identidades sexuais, independente das diferenças biológicas." Sendo assim, o termo discutido pelos autores vai além das perspectivas biológicas do que seria a vagina (órgão sexual feminino) ou o pênis (órgão sexual masculino), que neste caso designaria como sendo o sexo do indivíduo. O conceito de gênero parte do pressuposto de como a pessoa se sente e qual papel social ela assume, sendo este o de homem ou mulher.

De acordo com Galetti (2014), existem nos dias atuais vários movimentos em busca dos direitos iguais, como por exemplo, "A marcha das Vadias", que teve sua primeira edição em 2011 na cidade de Toronto, no Canadá e se expandiu por diversos países. No Brasil, inúmeras cidades protestam através dessa marcha reconhecida por ser uma manifestação mundial de produção artística de cunho político, que retrata a luta contra o sistema patriarcal, uma vez que tais produções acabam sendo uma maneira de dar visibilidade as mulheres (GALETTI, 2014). 
Tal movimento se deu em reposta a atitude de um policial canadense que afirmou que as mulheres que andavam como "vadias" provocavam a violência sexual, e por isso deviam ser responsabilizadas por tal ato. Essa declaração provocou insatisfação e revolta de mulheres em várias partes do mundo. Com o propósito de lutar pelo direito de autonomia de seus corpos, surge então tal marcha com a intenção de combater os discursos que responsabilizam e/ou culpam as mulheres que infelizmente são sexualmente violentadas (GALETTI, 2014).

Segundo Zarankin e Sarlerno (2008/2009), é perceptível o quanto a mulher é vista como indiferente quando comparada ao homem. Um retrato disso é a maneira negativa como a liberdade sexual da mulher é vista em sociedade. Entretanto, por mais que existam lutas e esforços da mulher na busca pela liberdade sexual, percebe-se que essa imagem negativa ainda é perpetuada até os dias atuais. Apesar de nos dias de hoje a mulher estar incluída nos diversos setores da sociedade, uma série de fatores ainda continuam a excluí-la, de modo que permanecem sendo vistas como fragilizadas e inferiores em relação ao homem. Enquanto o mundo masculino é associado a traços ativos, agressivos, fortes, seguros, independentes, públicos, racionais, a esfera feminina é vinculada a traços passivos, delicados, débeis, inseguros, dependentes, privados e emocionais.

De acordo com Oliveira e Rodrigues (2018), ainda existe uma divisão sexista no que diz respeito ao papel da mulher na sociedade. A mulher desde sempre foi conhecida como um ser frágil, pois ao passo em que o homem trabalhava para colocar comida em casa, a figura feminina era responsável pelas atividades domésticas e pelo cuidado para com os filhos. Além disso, a mulher não possuía liberdade sexual nem social; felizmente elas conseguiram ganhar mais espaço com o passar dos anos. No entanto, apesar de tantas lutas feministas, elaboração de leis e projetos de lei ainda é perceptível que as mulheres são vistas de maneira distinta dos homens, tachadas de incapacitadas no que diz respeito a realização de atividades ditas masculinas, além de serem inferiorizadas quando as fazem. É a partir de tais aspectos que o estudo acerca de gênero assume o papel de desmistificar as diferenças existentes entre homens e mulheres.

Em sua maioria, as representações de poder ligadas ao gênero são construídas na infância, como nas construções sociais de brincadeiras em que 
meninos, por exemplo, brincam com carrinhos e praticam futebol. Já as meninas são aquelas que brincam de casinha e com bonecas, destacando-se assim a forma como as crianças são diferenciadas e influenciadas desde os primeiros anos de vida a tornarem-se mulheres e homens com comportamentos pré-definidos de acordo com o seu sexo biológico (PEREIRA, OLIVEIRA, 2016).

Nesse sentido, a cultura, a família e a escola têm o importante papel de desmistificar sobre este assunto, pois tais elementos de gênero e grau de poder estão presentes no desenvolvimento de uma criança e acabam sendo condição de propagação desta ideia fundamentada pela dominação de poder. Observa-se, assim, que a sociedade desde muito cedo impõe o seu papel social a ser seguido, existindo uma relação de poder na qual o homem exerce o papel de dominador, cabendo à mulher a posição de submissão. (PEREIRA, OLIVEIRA, 2016).

\section{PERCURSO METODOLÓGICO}

Esse estudo foi de caráter qualitativo, pois levou em consideração a relação entre o mundo real e o sujeito, sendo um indissociável veículo entre a objetividade e a subjetividade dos indivíduos que não pode ser traduzida através de números, ou seja, não pode ser mensurado quantitativamente. Na pesquisa qualitativa, as interpretações dos fenômenos e os significados que Ihe são atribuídos são básicos e cruciais no processo da realização da pesquisa. Levando, portanto, a compreender o significado dos fenômenos observados sem a utilização de métodos e análises estatísticas para sua realização (PRODANOV, FREITAS, 2013).

Este estudo teve em sua estrutura a pesquisa de intervenção, definida como uma pesquisa que visa investigar elementos de uma história, no intuito de desenvolver uma intervenção direta ou indireta sobre as problemáticas encontradas. O propósito desta mediação não se visa algo imediato, mas ser uma construção de fundamentos que venham a transformar, a partir de uma análise sobre o mesmo, um determinado conceito, problema ou situação (ROCHA, AGUIAR, 2003). 
A pesquisa foi realizada em uma IES localizada no sertão do Nordeste. A amostra do público participante foi composta por vinte e dois alunas/os concluintes de um curso da área da saúde. Foram realizados três encontros em sala de aula com a turma, momento em que as pesquisadoras realizaram as atividades utilizando a temática sobre gênero e sexualidade. Para a elaboração desse artigo utilizou-se o material da primeira intervenção, que consistiu na aplicação de questionários que em seu escopo elencava diversas temáticas sobre os papéis sociais concebidos sócio e culturalmente por mulheres e homens seguido de várias opções de resposta; cada um deveria marcar a alternativa que mais se aproximava de sua concepção.

Posteriormente, um vídeo de curta duração intitulado "Acorda Raimundo, acorda!" 1 foi apresentado à turma. Este mostra a realidade de um casal hétero e seus papéis sociais. Os personagens expõem o cotidiano das suas relações em diferentes espaços, tanto no interior da dinâmica familiar, do trabalho e/ou na relação com amigos. Apresentado em formato de sátira, o vídeo retrata a inversão dos papeis sociais, uma vez que a realidade masculina é incorporada por uma mulher, assim como exibe a realidade feminina sendo interpretada pelo homem. Trata-se de uma situação que ironiza os papéis sociais de gênero, algo que é vivenciado por grande parte das mulheres atualmente $\mathrm{e}$, infelizmente torna-se naturalizado socialmente. Nos minutos finais do curta-metragem, as situações mostradas na obra são reveladas como um sonho de Raimundo, o personagem masculino. Após a exibição, as pesquisadoras incentivaram o debate e reflexões sobre a temática exposta, procurando fazer o mínimo de intervenções possível. 0 conteúdo coletado foi gravado mediante a autorização dos participantes e transcrito.

\section{RESULTADOS E DISCUSSÕES}

O presente estudo foi desenvolvido em uma IES localizada no alto sertão paraibano, com discentes concluintes de um curso na área da saúde. A amostra foi composta por 22 participantes, em sua maioria mulheres $(68,18 \%)$. No que diz

\footnotetext{
${ }^{1}$ Curta-metragem produzido no ano de 1990 e dirigido por Alfredo Alves. Pode ser encontrado no YouTube através do link: https://www.youtube.com/watch?v=snLsvVfF9X8.
} 
respeito à faixa etária do grupo, 91\% da turma tem entre 19 e 23 anos. Em relação à raça, $50 \%$ dos participantes se autodeclaram pardos. Já no que concerne ao estado civil, $72 \%$ dos estudantes afirma serem solteiras/os.

Como já posto, realizou-se um debate a partir da apresentação de um curtametragem denominado "Acorda Raimundo, acorda!", que retrata a temática das relações de gênero e os papeis sociais entre homens e mulheres. Percebeu-se durante a exibição do vídeo que a maioria dos participantes ria das situações retratadas pelo elenco. As risadas se sobressaíam principalmente quando mostradas cenas de afazeres domésticos sendo executados pelo personagem masculino, algo que não é tão comum de se ver em nosso cotidiano, já que ainda hoje é dominante o modelo patriarcal, no qual as funções domésticas em sua grande parte são destinadas à mulher.

Em oposição às risadas, uma aluna afirmou: "Não consigo nem rir das cenas, por mais que elas pareçam engraçadas isso acontece com as mulheres. $E$ isso me deixa angustiada". Após a apresentação do vídeo, foi aberto um espaço para o debate sobre o papel social do homem e da mulher exposto no curta-metragem, bem como as questões pautadas no questionário. No momento da discussão, a turma mostrou-se empenhada, participativa e colaborativa. Algumas questões emergiram das falas dos participantes, as quais são apresentadas e discutidas a seguir nos subtópicos: "Mulher deve se dar o respeito" X Liberdade da Mulher; Feminismo é o contrário de machismo?; Influência das brincadeiras infantis na sexualidade.

\section{“MULHER DEVE SE DAR O RESPEITO” X LIBERDADE DA MULHER}

A discussão se iniciou na ideia de que quando se pensa no cenário atual, a mulher possui mais liberdade do que antes e hoje a sociedade impõe menos padrões sobre a mesma. A ideia de que a mulher deve ficar em casa ou ser submissa ao marido vem sendo desconstruída. Porém, mesmo com esse pensamento de liberdade emergente para as mulheres, foi possível detectar ainda 
alguns estigmas a esse respeito, como nessa fala de uma aluna: "Na questão de roupa curta, eu deixaria de usar em respeito ao meu namorado". Quando foi questionada por uma das pesquisadoras por que usar uma roupa curta seria uma forma de desrespeito ao namorado dela, a aluna respondeu: "se outros homens soltassem piadas comigo na rua por causa da roupa seria um desrespeito com meu namorado".

A partir desta colocação, percebe-se que a mulher não julga o que é bom ou ruim para ela baseado em como se sente. Pelo contrário, se apoia no pensamento que um homem vai apresentar em determinada situação e isso é reforçado pelo estereótipo social de que a vontade do homem deve se sobrepor à da mulher e este deve impor a ela um comportamento moral de "moça direita". Com relação a essa afirmação, a turma reagiu e em sua maior parte argumentou sobre isso não ser culpa dela, afirmando que se ela gosta de roupas curtas ela deveria continuar usando. Entretanto, algumas/ns estudantes falaram que deveria se observar se a roupa era adequada à situação.

Com base nesse recorte de fala, é notório que, apesar de algumas/ns alunas/os afirmarem que a mulher tem liberdade com relação ao seu corpo e sobre o tipo de vestimenta que usará, o discurso que determinado tipo de roupa é inadequada ou desrespeitosa em ocasiões específicas ainda é muito presente. Este tipo de argumento é sempre direcionado à figura feminina, disfarçado com um pensamento de que "a mulher deve se dar o respeito". Entretanto, o homem não é alvo desses argumentos, reforçando a ideia de que o machismo ainda está presente e faz parte da nossa realidade. Sendo assim, não há uma reflexão perante a fala do que é ou não "inadequado", pois a decisão e discussão em torno desse aspecto sempre cabem à figura masculina, fazendo do homem o detentor do saber moral e ético, o que acaba tornando invisíveis as opiniões e falas da mulher, sendo ela posta na figura de imoral quando não aceita as imposições.

Segundo Cisne (2018), o atual cenário do feminismo busca encontrar justamente essa liberdade individualizante. No entanto, é preciso considerar as relações sociais existentes entre os sujeitos, as contradições, os conflitos e promover ações coletivas em torno de projetos que busquem dar enfoque a este assunto, já que não é suficiente pensar em categorizações ou na liberdade de 
maneira individualizante, apesar de ser importante considerar a subjetividade de cada indivíduo. Nesse contexto, as diversas opressões, explorações, preconceitos e discriminações que se expressam na sociedade são fruto das relações sociais de sexo, raça e classe, que se configuram a partir das diversas expressões das questões sociais. Nesse sentido, é a partir dessas intervenções coletivas que se pode superar tais questões e assim elaborar novas possibilidades para tornar as pessoas livres.

Este contexto não faz referência ao fato de dividir ou fragmentar as mulheres, mas sim de compreender as particularidades de cada uma e assim ter uma visão de entendimento valorizando sua totalidade, sem perder sua unidade e particularidade. A autora supracitada ainda faz referência à importância da cultura e da educação, bem como as representações no âmbito desses fatores de desigualdade, pois são eles que também propiciam a reprodução da ideologia patriarcal. A educação e a cultura nessa esfera se fazem de grande importância para o ato de pensar sobre os processos de formação de consciência. E a opressão sobre as mulheres se torna não como sendo um problema específico, mas algo que vem dessa questão do patriarcado que está diretamente relacionado a questões capitalistas. Por isso, a luta anticapitalista demanda também a luta contra o patriarcado e outras questões, como o racismo, por exemplo. (CISNE, 2018).

A liberdade da mulher é um tema que transcende a discussão de gênero e se sobrevêm em discursos de cunho econômico, político e social. Isso acontece já que a sociedade apresenta um discurso que apoia a igualdade entre os seres humanos, mas ao mesmo tempo é contraditória, e por vezes demoniza e tenta coibir qualquer ação da população para a obtenção desta igualdade e/ou liberdade.

\section{FEMINISMO É O CONTRÁRIO DE MACHISMO?}

Quando o grupo de pesquisadoras sugeriu que pensamentos como "a mulher deve se dar ao respeito" ou "a mulher fez por onde ser violentada”, entendeu-se que estes podem ser reflexos de um construto social fruto de uma sociedade machista e 
que tenta diminuir a responsabilidade dos homens em determinadas situações. Neste momento da discussão, uma aluna logo se manifestou: "detesto o machismo, mas também detesto o feminismo". Essa discente ainda afirmou que não deveria existir nenhum desses movimentos, deveria existir apenas a igualdade. Sem a necessidade de intervenção das pesquisadoras, várias/os alunas/os se manifestaram diante do discurso, explicando a colega o que seria o feminismo e de como algumas pessoas entendiam o movimento de maneira inapropriada.

A partir da provocação das pesquisadoras e do discurso da discente, ficou claro que as lutas feministas vêm sendo reconhecidas por uma grande quantidade de indivíduos, porém as informações do que é o movimento e o que ele apoia aparece de forma deturpada, gerando uma aversão dos indivíduos com o que eles acreditam ser a intenção do movimento. O objetivo principal dos grupos feministas é a igualdade dos gêneros. Por inúmeras vezes, esse posicionamento acaba sendo distorcido e enxergado como uma inversão no desequilíbrio dos papeis sociais de homens e mulheres. É possível perceber com esses discursos que os diálogos acerca do feminismo ainda não são bem difundidos no âmbito acadêmico. Sendo assim, para que exista uma mudança social nesse aspecto é necessário que a temática do feminismo seja discutida e debatida no âmbito acadêmico (NARVAZ, KOLLER, 2007).

O feminismo ainda carrega consigo um estigma social responsável por colocar o movimento no rol de grande desaprovação, sobretudo nos sujeitos que não conhecem a real finalidade do feminismo. Esse estigma acaba gerando um preconceito que afasta homens e mulheres das causas que buscam igualdade, sendo possível perceber também esse tipo de preconceito na Academia. Desse modo, torna-se imprescindível a discussão dessa temática do espaço acadêmico na tentativa de informar, levar conhecimento e desmistificar conceitos e concepções acerca de movimentos sociais que na grande maioria das vezes são compreendidos de maneira deturpada e errônea. 


\section{INFLUÊNCIA DAS BRINCADEIRAS INFANTIS NA SEXUALIDADE}

Outro ponto bastante discutido durante a intervenção diz respeito às brincadeiras infantis e as relações de gênero. Durante o debate, surgiram discursos sobre o fato de meninos brincarem com brinquedos socialmente destinados a meninas e vice-versa, sob a ideia de que isto poderia interferir na identidade de gênero e sexualidade das crianças. Viu-se que, por mais que este seja um tema bastante discutido, algumas pessoas ainda acreditam nessa influência. Isto pode ser observado a partir do relato de uma aluna, no qual ela afirma: "Eu acho, na minha opinião, que pode influenciar sim, um menino brincando de boneca daqui a pouco começa a falar todo mole". Diante dessa afirmação, uma das pesquisadoras fez o seguinte questionamento: "Como você acha que isso pode influenciar, e por quê?". A participante relatou que não sabia responder.

Esse acontecimento permite compreender que, a maneira que essas pessoas pensam acerca de tal temática é apreendida de modo que não os possibilitam pensar de outra maneira. Isto contribui para o processo de naturalização do sujeito, e que o próprio indivíduo não entende outra visão quando passa a ser questionado. De acordo com Pereira e Oliveira (2016), a construção histórica da infância está intimamente atrelada à maneira que a criança interpreta o mundo, e assim produz um comportamento diante da sociedade referente ao que vê e aprende até a sua vida adulta. Este fato pode dar suporte à fala de tal aluna, uma vez que pode ter aprendido essa posição frente ao assunto. No entanto, percebe-se a falta de coerência sobre o conhecimento ou fatos que defende em sua fala.

Pereira e Oliveira (2016) ainda dissertam acerca de como o brincar permite à criança dar significado e representar as coisas durante a infância. É a partir disso que a criança se apropria do pensamento que o homem pode ser superior à mulher e assim existem brinquedos de meninos ou de meninas. Entretanto, isso ocorre devido à forma como essas informações chegam até elas, porque a sociedade, a família e a escola, infelizmente, ainda ensinam que existem coisas de meninas e meninos, e é algo que vai sendo passado por gerações. 
Existem vários debates no presente momento acerca dessa temática, na intenção de esclarecer questionamentos e afirmações acerca disso, mas de acordo com o suporte dado pela psicologia, entende-se que não é o fato de uma criança brincar com "brinquedos de menina" ou vice-versa que ele se tornará gay ou a menina lésbica. Portanto, podemos afirmar que não existe brinquedo de menina ou de menino; existem brinquedos.

\section{CONSIDERAÇÕES FINAIS}

O governo, desde o golpe parlamentar de 2016, procura implantar na educação e demais setores sociais programas conservadores que valorizam ideias denominadas "bons costumes" e dignos de "um cidadão de bem". Esse pensamento retrógado desrespeita e distorce as questões de gênero e sexualidade, desconsidera e macula anos de lutas e conquistas dos movimentos sociais, pelas práticas do direito à diversidade, pelos direitos humanos e, por sua vez, atrasa novos diálogos que precisam ser feitos. Por mais que já se tenha avançado na aceitação e no entendimento dessas temáticas, ainda existe muito a ser desconstruído, repensado e transformado.

Compreende-se também como a sociedade aceita normas que são impostas como verdade absoluta, passa essas "verdades" para outros indivíduos, mas não busca uma justificativa plausível para essa norma que lhe foi exposta. Situações como essa apenas reforçam a necessidade de esclarecimento sobre tópicos relacionados à identidade de gênero e sexualidade nos diversos espaços e, inclusive, e, sobretudo, nos espaços acadêmicos, já que este é o espaço, por excelência, de formação de ideias e de profissionais.

Durante o processo de estudo acerca desse tema, notou-se como ainda é predominante o machismo na sociedade. As falas dos participantes remetem para a necessidade de discutir a temática do gênero e da sexualidade na Academia, visto que, apesar desse assunto ter certa visibilidade nos dias atuais, os indivíduos ainda confundem muito as novas denominações de gênero, assim como assunto num 
todo. Desse modo, é necessário que essas discussões façam parte do meio acadêmico como forma de desconstruir o pensamento que, na maioria das vezes, é passado de forma distorcida.

Desse modo, destaca-se a relevância da pesquisa para a construção desse conhecimento, com a finalidade de produzir e reconhecer outras realidades que por vezes são desconhecidas pela população geral e até mesmo por discentes que estão no meio universitário. Isto posto, percebe-se a importância de propagar a ideia de que temas como gênero e sexualidade possam permear também o âmbito acadêmico.

\section{REFERÊNCIAS BIBLIOGRÁFICAS}

BEAUVOIR, S. O segundo sexo 2: a experiência vivida. São Paulo: $2^{\mathrm{a}}$ ed., Difusão Europeia do livro, v. 2, p. 1-449, 1967.

CISNE, M. Feminismo e marxismo: apontamentos teórico-políticos para o enfrentamento das desigualdades sociais. Serv. Soc. Soc, São Paulo, n. 132, p. 211-230, 2018.

GALETTI, C. C. H. Feminismo em movimento: A Marcha das Vadias e o movimento feminista contemporâneo. In: Rede Feminista Norte e Nordeste de Estudos e Pesquisa sobre a Mulher e Relações Gênero, 10, 2014, Recife. Anais. Recife: Universidade Federal Rural de Pernambuco, 2014.

GURGEL, T. Feminismo e Luta de Classe: história, movimento e desafios teórico-políticos do feminismo na contemporaneidade. In: Seminário Internacional Fazendo Gênero, 9, 2010, Florianópolis. Anais. Florianópolis: Universidade Federal de Santa Catarina, 2010.

LOURO, G. L. Gênero, sexualidade e educação: uma perspectiva pós-estruturalista. $6^{\mathrm{a}}$ ed. Petrópolis: Editoras Vozes, 2003.

NARVAZ, M. G; KOLLER, S. H. A marginalização dos estudos feministas e de gênero na psicologia acadêmica contemporânea. Psico, Porto Alegre, v. 38, n. 3, p. 216-223, 2007.

OLIVEIRA, A. P; RODRIGUES, M. M. O papel da mulher na divisão sexual e social do trabalho. IN: Encontro Norte Mineiro de Serviço Social, 1, 2018, Montes Claros. Anais do I Encontro Norte Mineiro de Serviço Social. Montes Claros: Universidade Estadual de Montes Claros, 2018.

PEREIRA, A. S.; OLIVEIRA, E. M. B. Brincadeiras de meninos e meninas, cenas de gênero na educação infantil. Revista Reflexão e Ação, Santa Cruz do Sul, v.24, n. 1, p. 273-288, 2016.

PRODANOV, C. C.; FREITAS, E. C. Metodologia do trabalho científico: métodos e técnicas da pesquisa e do trabalho acadêmico. $2^{\mathrm{a}}$ ed. Novo Hamburgo: Feevale, 2013.

ROCHA, M. L; AGUIAR, K. F. Pesquisa - intervenção e a produção de novas analises. Psicologia: Ciência e profissão. Rio de Janeiro, v. 23, n 4, p. 64-73, 2003. 
ZARANKIN, A., SALERNO, M. A. "Sobre bonecas e carrinhos"; deconstruindo as categorias "feminino" e "masculino" no passado. Especiaria - cadernos de ciências humanas, llhéus, v. $11 / 12$, n. 20/ 21, p. 219-240, 2008/2009. 